\title{
Impacts of China's Strike Hard Policy on Forensic Evidence
}

\author{
Jiang Na \\ College for Criminal Law Science, Beijing Normal University, Beijing, China \\ Email: na.jiang@bnu.edu.cn
}

Received 3 April 2014; revised 4 May 2014; accepted 12 May 2014

Copyright (C) 2014 by author and Scientific Research Publishing Inc.

This work is licensed under the Creative Commons Attribution International License (CC BY). http://creativecommons.org/licenses/by/4.0/

c) (7) Open Access

\begin{abstract}
The media has reported numerous miscarriages of justice in China, some of which directly result from errors in forensic evidence as a main cause. Given that such miscarriages occurred under the influence of China's Strike Hard Policy, empirical studies on its impact on forensic evidence, particularly that leading to miscarriages of justice will be conducted at multiple levels with diverse research methods. The old policy officially took effect mainly from 1983 to 2005, when problems in forensic evidence significantly produced more miscarriages of justice. The old policy's impact on forensic evidence will be further explored based on data that were collected from experiments conducted with 394 questionnaires and 100 judges in four sample cities, just before and after the old policy was replaced with a balanced policy in late 2005 . Surveys to elicit the traits of forensic identification were used, as well as the exogenous imposition of the old policy to identify its negative impacts on forensic evidence, combined with new policy effects. The 2005 reform towards balancing leniency and severity is essentially inadequate to prevent errors in forensic evidence.
\end{abstract}

\section{Keywords}

Strike Hard Policy, Miscarriages of Justice, Problems in Forensic Evidence, Impacts

\section{Introduction}

China’s Strike Hard Policy that officially began from 1983 and ended in 2005 was intended to bring "severe and swift” punishment to criminals during many waves of anti-crime campaigns in an attempt to strike down and control serious crimes in China (Trevaskes, 2008). The old policy led to a high risk of more miscarriages of justice in practice and a leading cause of the increasing risk was problems in forensic evidences (He, \& He, 2012). The increasing miscarriages of justice have led to widespread concern about the negative impact of the old poli- 
cy on forensic evidence (Li, 2007) and to the observation that "severe and swift" punishments were frequently imposed even with unreliable or insufficient evidence. As a positive response to such impacts, the then secretary LUO Gan of the Party Central Political-Legal Committee introduced a new policy of "balancing leniency and severity" to replace the old one in December 2005. Since then, the new policy that involves lenient punishment had gradually become the guiding policy of China's justice practice, as reflected in more and more official documents or speeches in the political-legal system. This new policy undoubtedly influenced or guided the actual implementation of the 2005 Decision on Administration of Forensic Identification (Decision), though in 2007 justice organs were officially urged to "strike hard" again. The concerns over the 2005 reform (in the new policy and Decision) focus on preventing forensic disorder and errors in implementing the above policies.

China's Strike Hard policy provides a chance to identify the causal impact of the old policy on errors in forensic evidence. Miscarriages of justice are believed to result from the old policy as well as the use of forensic evidence obtained by illegal means. The negative influence of severe or swift punishment on the use of such unreliable forensic evidence has thus been considered as a key reason for the radical old policy leading to more errors in forensic evidence than the new balanced policy. For example, the old policy required all law-enforcement officials from the police, procuratorates and courts to closely work together in order to ensure imposing "severe and swift” punishment at the last defence line of justice. More attention to such punishment than justice, however, often comes with downsides concerning high expectations from the public and huge pressure from leaders, which attempted to meet the actual needs of so-called efficient anti-crime campaigns at the expense of criminal justice (Nestor, 2007). Among the downsides, errors in forensic evidence have been viewed as a result of the old policy which further led to the high risk of miscarriages of justice.

This article will start with the surveys of the reasons for forensic errors to explore the impact of the old policy itself and/or its combined impacts with the new one of balancing leniency and severity, on forensic identification. It will proceed with the survey of remedy for such errors and surveys of the relation between errors and wrongful convictions. As widely demonstrated, errors in forensic evidence have been highly considered correlated with other factors outside the following experimental setting (McConville, 2011). This research focused on the impact of the old policy on forensic evidence, which should be at the core of preventing such miscarriages of justice. The old policy was an influential factor contributing to them before the 2005 reform (Keith et al., 2013), but it is not possible to distinguish the sole effect of the biased use of forensic evidence before the above reform from the combined effect of the insufficient use of such evidence after the reform. In addition to experimental results, survey questions revealed that further reforms are needed to correct forensic error that increases miscarriages of justice.

\section{The Surveys of the Reasons or Remedy for Forensic Errors}

\subsection{Brief Introduction to Surveys}

The old policy cannot be considered as a natural distinction that enables us to separate out the impact of "severe and swift" punishment from that of the new balanced policy on forensic evidence. After the end of the old policy, surveys were conducted with participants including police investigators, public prosecutors, judges, defence lawyers and forensic experts from Beijing, Shanghai, Qingdao or Hohhot. The old policy was replaced in 2005, when a sample of 325 case files and 394 questionnaires were collected, in order to test and identify whether justice institutions strictly enforced the old policy before its abolition. The final sample involving 394 participants was collected from forensic agencies, the police, procuratorates and judiciary that provide, produce or use forensic evidence. The traits of such identification will be explored from the following aspects to reveal the old policy's impacts.

\subsection{An Analysis of Four Surveys}

There are three surveys on the reasons for forensic errors and one on the remedy for them. The first category of surveys focused on the former three topics. The last topic fell within the ambit of the survey on how to remedy for forensic errors in the identification procedure.

1) Limited knowledge of current forensic law or regulation

The questionnaire asked a single choice question: "Are you familiar with current forensic law or regulation in your work experience?” The possible answers were: (A) yes, I am familiar with them; (B) no, I am not familiar 
with them. Each respondent selected one of choice as an answer. The results of this questionnaire had revealed that many authorities who responded to the question did not know much of the 2005 reform on forensic examination.

For example, 67 out of 100 judges, 64 out of 100 public prosecutors, 82 out of 125 defence lawyers, 33 out of 44 police investigators, and all of 25 forensic experts picked “(A) yes, I am familiar with them”, as they said in answering the question. Correspondingly, the rest of them, e.g., 33 judges, 36 prosecutors, 43 defence lawyers and eleven police officers picked “(B) no, I am not familiar with them". In percentage terms, the groups who knew or were familiar with the new rules in questionnaires include all or $100 \%$ of 25 forensic experts, $75 \%$ of police investigators, $67 \%$ of judges, $65.6 \%$ of defence lawyers and $64 \%$ of prosecutors. Among them, forensic experts were ranked on the top, followed by police investigators, judges, defence lawyers and public prosecutors, from the highest $100 \%$ of such experts to the lowest $64 \%$ of prosecutors. In terms of territorial areas, 146 lawenforcement officers in Beijing expressed familiarity with the 2005 Decision, accounting for $73 \%$ of the total number of them from Beijing who were surveyed. Also, 42 (70\%) judicial officers from Qingdao and 37 (61.67\%) judicial officials from Hohhot expressed their familiarity in the survey.

\begin{tabular}{ccccc}
\hline Judges & Prosecutors & Defence lawyers & Police investigators & Forensic experts \\
\hline $67 / 100(67 \%)$ & $64 / 100(64 \%)$ & $82 / 125(65.6 \%)$ & $33 / 44(75 \%)$ & $25 / 25(100 \%)$ \\
\hline
\end{tabular}

The above statistics have illustrated a quite low level of knowledge of the new law among non-forensic officials. Clearly, a large percentage of prosecutor respondents in the questionnaire, e.g., $36 \%$, who often examine forensic evidence, were unfamiliar with current forensic law and regulation. But as for their daily work involving forensic identification, the judges selecting to handle cases on forensic evidence accounted for $82 \%$ among the total of 100 judges being interviewed, with 82 prosecutors for $82 \%$, 38 police investigators for $86.36 \%$ and 48 defence lawyers for $38.4 \%$. The higher percentage of justice officers handling forensic cases, over twice that of the relevant defence lawyers, would have contributed to much more officers who responded the above question with being familiar with the law, than the current percentage in the questionnaire. Unfortunately, prosecutors ranked at the bottom, even with a lower percentage of familiarity than that of defence lawyers related in the survey. The gap between expectation and result, hence, indicates that judicial bodies failed to pay more attention to existing laws concerned and partly explains why some of justice institutions did not obey current rules on forensic evidence in the criminal process. There is no wonder that forensic chaos and judicial shortfalls have widely persisted in China's forensic practice.

2) Poor implementation of the identification system

The survey asked: How was the implementation of the existing legislation on forensic identification do you think? Respondents were free to pick one of the four choices: (A) good, (B) poor, (C) partially good or poor, (D) no idea.

Among all of the 200 filling in the questionnaire form in Beijing, 95 or $47.5 \%$ chose "(A)" to answer that the identification system had been well implemented, while no-one picked "(B)" or "(C)" to tell any poor implementation. In Qingdao, 32 out of 60 people picking “(A)" (46.67\%) believed its implementation to be good and the one picking "(B)" (1.67\%) deemed it to be poor. In Hohhot, 34 out of 60 people (56.67\%) chose "(A)" to view the implementation to be good, six of them(10\%) chose "(B)" to consider it to be poor, and twenty of them (33.33\%) chose "(C)". The survey result shows that the implementation was unsatisfactory in all of cities surveyed.

Among the respondents, 67 of all 100 judges (67\%) who filled in the questionnaire forms picked "(A) good" and four judges chose "(B) poor", with the rest to pick "(D) no idea”. The percentage of judges who picked "(A)" is the highest among that of justice officers. Similarly, 27 of 44 police investigators (61.36\%) maintained a high rate of picking "(A)", with one (2.27\%) to choose "(B)" and the rest to choose "(C)". It demonstrates that slightly over half of such officers were satisfied with the implementation of forensic identification, and that nearly half of them were dissatisfied in the survey.

Different from them, 43 of the total 100 prosecutors, less than half, picked "(A)" to maintain that it had been well implemented, whereas two of them picked "(B)" to view the implementation to be poor. Similar to the rate of prosecutors, there are 54 of 125 defence lawyers (43.2\%) who picked "(A) good", apart from seven of the total (5.6\%) who chose "(B) poor”. At the bottom of ranking, only $12 \%$ or three out of the 25 forensic experts 
picked “(A) good”, with $22 \%$ or $88 \%$ of them to choose "(C) partially good or poor". Although no expert chose "(B) poor”, the 22 of them were still very unhappy with the implementation. Forensic experts, who understood the implementation better than other justice officers, were hence most dissatisfied with it. This reveals that the implementation was not satisfying, but biased.

3) Abolition of forensic agencies affiliated to the police

Most of forensic identification cases are still conducted by forensic agencies inside the police, though the National People's Congress's 2005 Decision is intended to solve the problem of appraiser management against justice. Given the natural relation of their interest with police forensic sectors, the experts who appraise the forensic evidence are not independent from the police or impartial with forensic identification. Social sectors that are funded and administrated by domestic non-governmental organizations are involved in very few cases. Whether to abolish police forensic sectors or not has been a focus in further reform on the above Decision to better implement the new policy of balancing leniency and severity.

The survey asked: Which one of the following ways do you think is likely to solve the problem of biased forensic identification? Answers included: (A) maintain police forensic sectors, (B) abolish them, (C) no idea. Among the total of 25 questionnaires from forensic experts in the three cities, there are five experts in Hohhot who picked (A) to favour maintaining them and four who picked (B) to argue for their abolition, while five experts in Qingdao and eight in Beijing picked (A). Overall, 72\% of forensic experts picking (A) thought that such sectors should be retained and 16\% picking (B) argued for their abolition to prevent biased identification and forensic error. The rest of such experts chose "(C) no idea”. Clearly, nearly three-fourths of experts argued against abolition and less than one-sixth of them for it, differing from the expectation of ensuring their independent role in forensic work.

Again, such a discrepancy appeared in the following legal professionals of diverse occupations. More police investigators and forensic experts deemed abolishing police sectors not to be a potential way to solve the above problem. Among the respondents from the group of police investigators, twelve in Hohhot, eleven in Qingdao and nine in Beijing picked (A) to argue for retaining forensic sectors inside the police, whereas one in Qingdao and five in Beijing picked (B) to favour abolishing them. The overall percentages in the above cities are about $72.73 \%$ of police investigators picking (A) in favour of retaining them, about $13.64 \%$ of them picking (B) against retaining them. The rest of such police investigators picking (C) expressed "no idea" about how to solve the above question.

Even inside the investigating authorities, there were still twelve of 44 police investigators $(27.27 \%)$ who picked (B) or (C) not to support retaining police forensic sectors, either preferring their abolition to choose (B) or expressing "no idea" on the matter to choose (C). From the Hohhot statistics, forensic experts supporting abolition accounted for about $44 \%$ of the total number of them, in a sharp contrast with $90 \%$ who did not support it, over which the percentage of Hohhot police investigators against it ranked on the top of the three cities. Differently in Beijing, police investigators who supported non-abolition accounted for $50 \%$ only, while forensic experts did account for over $88 \%$ of such experts sampled in the survey.

4) Initiation of the identification procedure

Following questionnaires on forensic errors, further research focused on 325 case files. Among the sampled case files collected from various courts, 319 cases (or approximately 98.15\%) of the total, involve the procedure for forensic identification, which was initiated by the police during their investigation very often. For instance, through this identification procedure, many forensic evidences, e.g., who committed the alleged crime or whether certain items were involved in the crime, could be identified to determine the guilt or innocence of the accused. Also, this procedure can be initiated by others at trial, albeit in six cases (or less than 1.85\%) among all cases sampled, including three ones with judges' initiative to initiate it.

Specifically, in both Beijing and Shanghai, the identification procedure for all of the cases surveyed was started by the police on their initiative at the stage of investigation. Albeit in one case where victims applied for identifying their injuries at trial in 2007, their application ended with rejection that cannot start the procedure for forensic identification in court. Similarly, in Qingdao and Hohhot the vast majority of cases sampled were initiated by the police as the investigating authorities on their own initiative at the investigation stage. For example, in Qingdao they launched the procedure for forensic identification in 25 cases in 2005, 27 cases in 2006 and 38 cases in 2007 during their investigation. Accordingly, there were only few cases with others' initiative to start or apply for the identification procedure at trial. For instance in 2007, judges started the above procedure at trial in one case, and the application of the parties initiated one more too, in Qingdao. Differently in Hohhot, the only 
exception in this year was a case involving the procedure, which was launched upon an application from the parties and approval by judges. Additionally, in Qingdao, judges started it at trial in two more cases in 2005, but did not approve an application for re-identification in another case in the year, or review another application before the parties' withdrawal in 2006.

This set of data shows that the serious imbalance between justice officers' power to initiate the procedure for forensic identification and the parties' right to apply for that. To remedy the bias of forensic identification towards swift and severe punishment in practice, there is a very need to balance the above power and right for better checking and correcting forensic errors. But clearly, the imbalance cannot reach the desired goal but ended with a failure in preventing such errors that may directly lead to wrongful convictions. Also, the police often dominated the process of forensic identification so that judges seldom audited or challenged forensic evidence produced by the investigating authorities at trial. This further deteriorated the negative consequences of the above imbalance. Specifically, the identification procedure was mainly initiated by police investigators who acted ex officio during forensic investigations, in the vast majority of all cases sampled. This poor situation demonstrated that judges had very few chances to initiate the procedure at trial, not to mention the parties whose application for starting it need judges' approval. Their relatively low level of participation in forensic identification lied in the fact that prosecutors usually passively accepted the forensic conclusions made by their police colleagues without necessary audit or check.

Also, many of individuals' active applications for initiating forensic investigations had been rejected by courts even against justice. The general reluctance of courts to allow for forensic investigations may largely discourage individuals to apply for forensic identification, further deteriorating inadequate restraint on forensic identification made by the police. It is because the justice system of China is greatly based on the mutual restraint between the police, prosecutors and judges in order to correct errors and prevent injustices by law. Any breaches of such necessary restraint would lead to many forensic errors and resulting criminal injustice. Undoubtedly, the tendency of judges to accept police investigators advice over forensic experts' opinions broke the due balance between them, but improperly enhanced the police's supremacy over the process and worsened their negative influence on forensic evidence. In turn, long-standing close cooperation between both institutions made judges even more likely to take the police's advice on forensic evidence in the future as a vicious cycle in practice.

\section{The Survey of the Relation between Errors and Convictions}

\subsection{Brief Introduction to Surveys}

From January 2005 to March 2007, I went respectively to Beijing, Shanghai, Qingdao and Hohhot for research on the following topics. The questionnaire with interviews and examination of case files were combined to improve the reliability of results in the following surveys. Among the questioned, all of judges in the surveys answered the relevant questions.

\subsection{Analyses of the Survey Results}

1) Impacts of forensic conclusions on judges' verdicts

Concerning the relation between forensic errors and wrongful convictions, the first survey asked of respondents: Do you think that forensic conclusions have great impacts on your verdicts? Potential answers are: (A) Yes; (B) No.

Among the questioned on impacts, 82 of all 100 judges sampled (or $82 \%$ ) chose (A) who stated the great impact which forensic conclusions had on their final decisions and the rest picked (B) to expressly maintain a dividend opinion against them. In Hohhot, 25 out of 30 judges (or about 83\%) in the survey thought that forensic conclusions had great impacts on verdicts because they took into account such conclusions as the focus of evidence, whereas another three judges (or 10\%) deemed no special effects of forensic evidence on verdicts. In Qingdao or Shanghai, all of eleven judges surveyed agreed with forensic conclusions' great impact on their decisions, as did 35 out of the 48 surveyed judges (or about 73\%) in Beijing.

The great impacts of forensic conclusions on verdicts can be proved by the judgments of case files sampled. For instance, in 73 judgements from the 74 case files (or about 98.65\%) collected in Shanghai, judges examined whether to adopt identification conclusions or not in the contents of judgments. Among the 96 case files from Qingdao, there are a total of 68 cases (or about 70.83\%) in which judges responded to forensic conclusions in 
the contents of their verdicts. With a gradual increase for each year, thirteen cases mentioning them occurred in 2005, followed with twenty-one cases concerned in 2006 and 34 cases related in 2007. Among 60 case files from Inner Mongolia, judges elaborated their opinions on whether to adopt forensic conclusions or not in their final verdicts in 47 forensic cases (or about 78.33\%) only. In total, judges addressed their impacts in about 81.74\% of 230 cases in the three areas. The high impact of that judges' forensic conclusions had on their final disposition of the cases sampled has illustrated the importance of the forensic identification system in justice practice.

2) Handling multiple identification conclusions for the same fact

Also, the second survey further answered a multiple-choice question: Which one of the following ways do you think is most likely to prevent false evidence against the accused and inhibit wrongful convictions from occurrence, in handling forensic conclusions on one fact? Respondents could give diverse answers: (A) adopting the conclusions made by forensic sectors at a higher administrative level; (B) adopting the conclusions made by the more authoritative experts; (C) adopting final conclusions; (D) adopting the majority view; (E) adopting the conclusions made by forensic experts with higher ranks or education levels; (F) no set method of determining the conclusions, or $(\mathrm{G})$ no idea about them.

Of the respondents, twenty-two out of 30 judges (or 73.33\%) involved in the Hohhot survey picked (A) and tended to adopt the conclusions made by forensic sectors at a higher level of administration. Among the 30 , four judges (or 6.67\%) picked (B) and tended to consider the personal factors of forensic experts and adopt the conclusions of the more authoritative experts. Out of these four, two judges also picked (C) and tended to admit final conclusions while the other two judges also chose (C) and maintained that the majority view should be adopted between two or among more conclusions. In Qingdao, five out of eleven judges surveyed (or 45.45\%) picking (A) tended to admit the conclusions made by forensic sectors at a higher administrative level. Among the 11, three judges (or 27.27\%) picking (B) and (E) tended to consider the personal factors of forensic experts and adopt the conclusions made by more authoritative experts or by forensic experts with higher ranks or education levels. Out of them in Qingdao, the two (or 18.18\%) picking (C) preferred those from the finally conducted investigation in particular cases and one (or 9.09\%) picking (G) had no idea about them at all. Out of 48 judges in the Beijing survey, eighteen (or 37.5\%) picking (A) tended to admit conclusions made by forensic sectors at a higher level, twelve (or 25\%) picking (D) preferred those by more authoritative experts, seven (or 14.58\%) picking (C) admitted final conclusions, eight (or 16.67\%) picking (D) adopted a majority view and three (or 6.25\%) picking (F) had no set method of determining which experts or results to believe.

These data show that judges in the three cities were inclined to admit identification conclusions made by forensic sectors at a higher level of administration as the first choice, followed with those provided by a more authoritative expert as the second. Both of choices, namely, (A) and (B), accounted for about $71.91 \%$ of the total number sampled. In practice, both the level of forensic sectors and authority of forensic experts had been the main criteria on which judges decided final conclusions through repeated forensic investigations, as demonstrated from the above answers. Given the preference that conclusions are popular with judges as favorable evidence, numberous cases are flocking to forensic sectors at a higher level or forensic experts with strong background. Hence, there was less workload in social or lower-level sectors based on their minor role in forensic work. Particularly in Hohhot, it was obvious that judges relied on the level of sectors, whereas in Beijing judges relying on the level were as many as those making decisions based on the authority of forensic experts. The selection of forensic conclusions from diverse ones on the same fact appeared to be arbitrary and anomalous, without a scientific or reasonable rule to obey. No false evidence against the accused can be prevented from use to reduce the high risk of wrongful convictions concerned.

\section{Conclusion}

Although findings were obtained from the survey in sample cities, the results are generalizable to other areas of Mainland China where the influence of the old policy still exists, even if the new policy has been implemented in recent eight years. Previous work suggests there was no much difference between the impact of the abandoned old policy and that of the new policy on forensic errors. Actually, it is same to the impact of new changes in the 2005 Decision without substantive progress on forensic work but with fundamental flaws leading to errors. However, the effect of the old policy on forensic errors long after its introduction may differ from what has been found here, because the balanced new policy calls for reliable forensic evidence in well balancing leniency and 
severity. Against the background of implementing the 2005 reform, including both the Decision and the new policy, the old policy's effect on forensic evidence is expected to be minimized so as to better prevent biased identification or forensic error potentially leading to wrongful conviction. Surveys to elicit the traits of forensic identification have identified the old policy's diverse impacts on forensic evidence, especially in and after implementing the 2005 reform in China's forensic practice.

\section{References}

Trevaskes, S. (2008). The Death Penalty in China Today: Kill Fewer, Kill Cautiously. Asian Survey, 3, 393-413. http://dx.doi.org/10.1525/as.2008.48.3.393

He, J. H., \& He, R. (2012). Empirical Studies of Wrongful Convictions in Mainland China, The University of Cincinnati Law Review, 80, 1277-1292. http://scholarship.law.uc.edu/uclr/vol80/iss4/11

Li, Jianming 李建明 (2007). Xingshi cuoan de shen cengci yuanyin 刑事错案的深层次原因. China Legal Science, 3, 3144.

Nestor, P. D. (2007). When the Price Is Too High: Rethinking China’s Deterrence Strategy for Robbery. Pacific Rim Law \& Policy Journal, 2, 525-550.

McConville, M. (2011). Criminal Justice in China: An Empirical Inquiry (p. 132). Cheltenham: Edward Elgar Publishing. http://dx.doi.org/10.4337/9780857931917

Keith, R. C., et al. (2013). China’s Supreme Court (pp. 131-132). London: Routeledge. 